\title{
Clinical Study of Valvular Heart Disease
}

\author{
Siddharth Vinod Lakhani', Vijay Krishna Joglekar ${ }^{1}$ \\ ${ }^{1}$ Medicine Dept, GMC and Sir JJ Hospital, Byculla, Mumbai, India.
}

Institute at which research was conducted: Grant Medical College \& Sir JJ Hospital, Mumbai, India University Affiliation of Thesis: Maharashtra University of Heath Sciences

Year of Acceptance: 2013

\section{Address of Correspondence}

Dr Siddharth Vinod Lakhani

401-402 Chetan Bldg, Opp Popular Hotel, Hingwala Lane, Ghatkopar East.mumbai 400077

E mail: siddharthlakhani1@gmail.com

Abstract: Background: A thorough understanding of the various valvular disorders is important to aid in the management of patients with VHD. We herby thus study various presentations, distributions, complications and severity of patients presenting with valvular heart disease.

Materials and methods: 250 patients with valvular heart disease were enrolled and studied for demographic details,clinical presentation and complications

Results: In study of 250 patients ,the most common valvular lesion was mitral regurgitation 114 (45.6\%) out of which 75 (30\%) were Isolated MR, MS with MR 30(12\%) patients, MR with TR 7(2.8\%) patients and MR with AR with TR 2(0.8\%).other parameters as detailed in thesis.

Conclusion: Each valvular heart lesion presents with varied demographic characteristics with peculiar clinical presentation and complication rate.

Keywords: Valvular heart disease, demographics, presentations, complications, severity

\section{THESIS SUMMARY}

\section{Introduction:}

Valvular heart disease(VHD) is result from damage or deterioration of the valve structures leading to some degree of stenosis, incompetence or both. Although valvular heart disease is less frequent than coronary disease, heart failure or hypertension, it is of reasons because firstly VHD Is still common and often requires intervention and secondly important changes has occurred as regards to presentation and complication over recent years.A better understanding of the natural history coupled with the major advances in diagnostic imaging, interventional cardiology, and surgical approaches have resulted in accurate diagnosis and appropriate selection of patients for therapeutic patients aged 12 years and above are interventions. Athorough understanding of considered 'adult' and are managed by the the various valvular disorders is important to adult Medicine. There is no upper age limit. A aid in the management of patients with detailed clinical history including including VHD.We herby thus study various various symptoms, pasthistory of rheumatic presentations, distributions, complications fever, followed by systemic examination was and severity of patients presenting with done. Specific findings of rhythm of pulse valvular heart disease.

\section{Materials and methods:}

We enrolled 250 cases of valvular heart disease patients in the present study. Patients with native valvular heart disease of age $>12$ years. cases of newly diagnosed adult patients with valvular abnormalities presenting to the medicine and Cardiology Unit from May 2010 to October 2012. All rate, blood pressure, raised jugular venous patient. A detailed cardiovascular systemic examination for specific findings of character of apex beat, character of $\mathrm{S} 1$, and $\mathrm{S} 2$, type of murmur were noted for all patients.A chest $\mathrm{x}$ ray postero anterior view was done in all patients and Cardio thoracic ratio was noted in all patients.A 12-lead electrocardiogram was done in all the patients to look for rate, rhythm, chamber pulse, oedema feet, were noted for each 
enlargement/hypertrophy .Each patient underwent echocardiographic evaluation and parameters like Left atrial (LA) dimensions, left ventricular ejection fraction (LVEF), left ventricular end diastolic dimension (LVIDD), left ventricular end systolic dimension (LVIDS), valve area for stenotic lesions, pulmonary artery pressure (PASP), for stenotic lesions mean gradient was calculated, and for regurgitate lesions Vena contracta and jet width was calculated.

\section{Results:}

Tin study of 250 patients, the most common valvular lesion was mitral regurgitation $114(45.6 \%)$ out of which $75(30 \%)$ were Isolated MR, MS with MR 30(12\%) patients, MR with TR 7(2.8\%) patients and MR with AR with TR 2(0.8\%). There were $78(31.2 \%)$ cases of mitral stenosis , with 25(10\%) of Isolated MS, MS with MR 30(12\%), MS with TR 13(5.2\%), MS with AS 5(2\%), MS with AR $3(1.2 \%)$ and MS with AR with TR 2 (0.8\%). There were 68 (27.2\%) cases of aortic regurgitation with $35(14 \%)$ of Isolated AR and $25(10 \%)$ of patients with AS with AR, $58(23.2 \%)$ cases of aortic stenosis out of which 28 (11.2\%) oatients with Isolated AS. There were $24(9.6 \%)$ of tricuspid regurgitation all associated with mitral or aortic lesions and no cases of tricuspid stenosis . It is noted that Isolated MS (25) was more common in females $(15)$ than male $(10)$ patients, in all other cases the lesions were more common in male patients. In case of mixed valve lesions MS with AR (3) was also more common in female (2) patients, all other cases of mixed lesions were more common in male patients. Dyspnea was present in 22(88.8\%) patients.Dyspnea was present in $100 \%$ cases of Isolated MS, with $5(20 \%)$ patients of class I dyspnea, 7 $(28 \%)$ patients with class II , $11(44 \%)$ patients with class III dyspnea, and $2(8 \%)$ patients with class IV dyspnea.In cases of Isolated MR dyspnea was present in $94.7 \%$ patients with $14(18.7 \%)$ patients with class I dyspnea, 32(42.7\%) patients with class II , $21(28 \%)$ patients of class III, and $4(5.3 \%)$ patients with class IV dyspnea. $4(5.3 \%)$ patients did not have dyspnea. In cases of Isolated AR dyspnea was present in $88.6 \%$ patients with $5(14.3 \%)$ patients with class I dyspnea , 16(45.7\%) patients with class II , 9(25.7\%) patients of class III, and 1 (2.9\%) patients with class IV dyspnea. $4(11.4 \%)$ patients did not have dyspnea. In cases of Isolated AS dyspnea was present in $82.1 \%$ patients with $2(7.1 \%)$ patients with class I dyspnea, 16(57.1\%) patients with class II , $5(17.9 \%)$ patients of class III, and no patients with class IV dyspnea. $5(17.9 \%)$ patients did not have dyspnea. In cases of mixed lesions dyspnea was present in $82.7 \%$ patients class I dyspnea with 7 ( $8 \%$ ) patients Out of which 3 were with AS with AR, 3 with MR.class II dyspnea $33(37.9 \%)$ patients with out of which, 13 were with MS with MR, 6 with MS with TR, 1 with MS with AS , 8 AS with AR, 2 with MR with TR, 2 with MS with AR with TR and 1 with MS with AR.

\section{Conclusion:}

Most common age of presentation of valvular heart disease was 4150 years $(35.2 \%)$. Male to female ratio was $1.48: 1$. The most common valvular lesion was mitral regurgitation in $45.6 \%$ patients. Valvular lesions were more common in male patients except in cases of Isolated MS and MS with MR were there was female predominance. Most common presenting symptom was dyspnea $(88.8 \%)$, second most common palpitations (79.2\%), followed by chest pain $(56 \%)$ and syncope (4.8\%). Syncope was seen mainly in cases of Isolated AS 10 $(35.7 \%)$. Pulse was irregularly irregular in 55 (22\%) patients ,. Irregularly irregular pulse was more common in patients with MS (28\%). Mean systolic blood pressure(in $\mathrm{mm}$ of $\mathrm{Hg}$ ) in Isolated MS is
$121.68,125.52$ in Isolated MR, 125.26 in Isolated AR, 125.93 in Isolated AS , 122.02 in mixed valve lesion.Mean diastolic blood pressure(in $\mathrm{mm}$ of $\mathrm{Hg}$ ) in Isolated MS is 73.60 , 78.77 in Isolated MR , 45.80 in Isolated AR, 76.50 in Isolated MS and 70.23 in mixed valve lesion. On ECG Atrial fibrillation was more common in patients with Isolated MS (28\%) P Mitrale was more common with Isolated MS (93.33\%), P Pulmonale was More common in patients with Isolated MS (36\%).RVH was most common with Isolated MS 48\%, LVH was most common in patients with Isolated AS 64.29\%.on ECHO Mean LA Size(in mm) in Isolated MS is 45.36, Isolated MR 42.20, Isolated AR 28.26 ,Isolated AS 27.21. Mean LVIDD(in mm) in Isolated MS is 46.40, Isolated MR 54.61, Isolated AR 28.26, Isolated AS 27.21. Mean LVIDS(in mm) in Isolated MS is 30.24, Isolated MR 44.71, Isolated AR 45.66 ,Isolated AS 41.25. Mean Ejection fraction in Isolated MS is 59.44, Isolated MR 59.01, Isolated AR 58.54, Isolated AS 60.71. Mean mitral valve area in Isolated MS is 1.16 , mean aortic valve area in Isolated AS 1.29. Mean gradient across mitral area in Isolated MS is 9.56, Mean gradient across Aortic area in Isolated AS is 32.39. Mean PASP in Isolated MS is 43.60, Isolated MR 37.57, Isolated AR 28.06 ,Isolated AS 30.25. Mean vena contracted in case of Isolated MR 0.39, in Isolated AR 0.41, Mean jet width Isolated MR 28.09, Isolated AR 41.91. Most common complication was congestive heart failure $26.8 \%$, followed by atrial fibrillation $22 \%$, followed by infective endocarditis $6.8 \%$, and stroke (hemiparesis) in $2 \%$.

\section{Key Words:}

Valvular heart disease, demographics, presentations, complications, severity

\section{Bibliography}

1. H.David humes. Valvular heart disease. In Kelley's essentials of internal medicine,2nd edition. Philadelphia,LIPPINCOTT

WILLIAMS \& WILKINS,2001;106.

2. Khawaja Tahir Mahmood, Mashal Anees, Ayesha Asghar. Valvular Heart Diseases - A Review.JBIOMED SCI and RES 2011;3:315-21.

3. World Health Organization. Rheumatic fever and rheumatic heart disease: Report of WHO expert consultation. Geneva, 29 Oct-1 Nov 2001. World Health Organ Tech Rep Ser 2004;923:1-122.

4. Carapetis JR. Rheumatic heart disease in developing countries. $N$ EnglJ Med

2007;357:439-41.

5. Carpetis JR, mc Donald $m$, Wilson NJ. Acute rheumatic fever. Lancet 2005;366:115-68.

6. Marijon E, Mirabel M, Celermajer DS, Jouven X. Rheumatic heart disease. Lancet. 2012 Mar 10;379(9819):953-64.

7. Duffin JM. The cardiology of RTH Laënnec. Med Hist. 1989;33:42-71.

8. Flaxman N. The hope of cardiology: James Hope (1801-1841). Bull Hist Med. 1938;6:1-21.

9. VanderVeer JB. Mitral insufficiency: historical and clinical aspects. Am J Cardiol. 1958;2:5-10. 
10. Rolleston H. The history of mitral stenosis. Br Heart J. 1941;3:1-12.

11. VaslefSN, Roberts WC. Early descriptions of aortic valve stenosis. Am Heart J. 1993;125:1465-1474.

12. Vaslef SN, Roberts WC. Early descriptions of aortic regurgitation. Am Heart J. 1993;125:1475-1483.

13. Hanna IR, Silverman ME. A history of cardiac auscultation and some of its contributors. Am JCardiol. 2002;90:259-267.

14. Silverman ME, Fleming PR, Hollman A, et al. British Cardiology in the 20th Century. London: Springer, 2000.

15. Boudoulas H, Vavuranakis M, Wooley CF. Valvular heart disease: the influence of changing etiology on nosology. J Heart Valve Dis. 1994;3:516-526. [PMID: 8000586].

16. Suman Bhandari, K Subramanyam, N Trehan. Valvular Heart Disease: Diagnosis and Management. Japi 2007;25:575.

17. Shaver JA. Cardiac auscultation cost-effective diagnostic skill. Curr Probl Cardiol 1995;20:441-530.

18. Gatzoulis MA. Heart and Great vessels. In, Gray's Anatomy The Anatomical Basis of Clinical Practise. Standring S. 40th Edition. Spain. Elsevier Churchill Livingstone:959-87.

19. TK Mishra. Acute Rheumatic Fever and Rheumatic Heart Disease :Current Scenario. Journal, Indian Academy of Clinical Medicine 2007;Vol. 8, No. 4: 324-30

20. Periwal KL, Gupta BK, Panwar RB, Khatri PC, Raja S, Gupta R. Prevalence of rheumatic heart disease in school children in Bikaner: An echocardiographic study. J Assoc Physicians India.2006;54:279-82.

21.S Padmavati. Rheumatic heart disease: Prevalence and preventive measures in the Indian subcontinent. Heart 2001;86:127.

22. Jonathan R. Carapetis . Rheumatic heart disease in Asia . Circulation 2008;118:2748-50.

23. JL d'Arcy, B D Prendergast, J B Chambers, S G Ray, B Bridgewater

Valvular heart disease: the next cardiac epidemic. Heart 2011;97:91-93.

24. Bernard Iung , Gabriel Baronb, Eric G. Butchart, Francois Delahaye,Christa Gohlke-Ba"rwolf, Olaf W. Levang, Pilar Tornos,Jean-Louis Vanoverschelde, Frank Vermeer, Eric Boersma,Philippe Ravaud, Alec Vahanian. A prospective survey of patients with valvularheart disease in Europe: The Euro Heart Surveyon Valvular Heart Disease. European heart journal 2003;24;1231-43.

25.S. RAMAKRISHNAN,SHYAM S. KOTHARI, RAJNISH JUNEJA, BALRAM BHARGAVA,ANITA SAXENA,VINAY K. BAHL. Prevalence of rheumatic heart disease: Has it declined in India? . THE NATIONAL MEDICAL JOURNAL OF INDIA VOL. 22, NO. 2, 2009.

26. Rajeev Bhardwaj, Arvind Kandoria, Rajeev Marwah, Piyush
Vaidya, Bakshish Singh, Pravesh Dhiman, Avinash Sharma. Prevalence of Rheumatic Fever and Rheumatic Heart Disease in Rural Population of Himachal- A Population Based Study JAPI mAy 2012 VOL. 60.13-15.

27. S.padmavati .Epidemiology of cardiovascular disease in India. Rheumatic heart disease.Circulation 1962;25:703-10.

28. Karen Sliwa, Melinda Carrington, Bongani M. Mayosi, Elias Zigiriadis,Robert Mvungi, and Simon Stewart. Incidence and characteristics of newly diagnosedrheumatic heart disease in Urban African adults:insights from the Heart of Soweto Study. European Heart Journal 2010;31:719-72.

29. Tornos.p . valvular disease in women.Rev esp cardiol 2006;59(8);831-36.

30. Bernard Iung, Gabriel Baronb, Eric G. Butchart, Francois Delahaye,Christa Gohlke-Ba"rwolf, Olaf W. Levang, Pilar Tornos,Jean-Louis Vanoverschelde, Frank Vermeer, Eric Boersma,Philippe Ravaud, Alec Vahanian. Valvular heart disease in community :a European experience. Curr probl cardiol 2007;32;609-61.

31. McLaren MJ, Hawkins DM, Koornhof HJ, Bloom KR, BramwellJones DM, Cohen E, Gale GE, Kanarek K, Lachman AS, Lakier JB, Pocock WA, Barlow JB. Epidemiology of rheumatic heart disease in black school children of Soweto, Johannesburg. BMJ. 1975; 3: 474-478.

32. J.N Berry. Prevalence survey for chronic rheumatic heart disease and rheumatic fever in northern India. British heart journal 1972:34; 143-49.

33. Kawanishi DT, Rahimtoola SH. Mitral stenosis. In: Rahimtoola SH, ed. Valvular Heart Disease II. St. Louis: Mosby, 1996:8.1-8.24

34. Bongani M.Mayosi,Jonathan R.Carapetis. Acute Rheumatic fever. In, Hurst's The Heart. Fuster V, Walsh RA, O'Rourke RA, Wilson PP. 12th edition. USA. McGraw Hill:1691-93.

35. Rheumatic fever and rheumatic heart disease: report of a WHO expert consultation: Geneva, 29 October-1 November 2001. WHO Tech Rep Ser.2001; 923:20.

36. Boudoulas H, Vavuranakis M, Wooley CF. Valvular heart disease: the influence of changing etiology on nosology.J Heart Valve Dis. 1994 Sep;3(5):516-26.

37. HARISIOS BOUDOULAS. Etiology of Valvular Heart Disease in the 21st Century. Hellenic J Cardiol 2002;43:183-188.

38. Toledano F, Crespín M, Ortiz MR, Mesa D, Romo E, Delgado M, Suárez de Lezo J. Etiologic spectrum and clinical features of mitral regurgitation in a Spanish population. JHeartValveDis. 2012 May;21(3):293-98.

39. Jagmeet P. Singh, MD, DPhil,Jane C.Evans, MPH,Daniel Levy, MD, Martin G.Larson, ScD, Lisa A. Freed, MD,Deborah L. Fuller, RDCS, BirgittaLehman, RDCS, and Emelia J. Benjamin, MD, ScM. Prevalence and Clinical Determinants of Mitral, Tricuspid, 
and Aortic Regurgitation(The Framingham Heart Study)Am J Cardiol 1999;83:897-902.

40. Hamza Arslan Aurakzai, Shahid Hameed, Ahmad Shahbaz, Salman Gohar, Moqueet Qureshi, Habibullah Khan, Waqas Sami, Muhammad Azhar, Jawad Sajid Khan. ECHOCARDIOGRAPHIC PROFILE OF RHEUMATIC HEART DISEASE AT A TERTIARY CARDIACCENTRE.J Ayub med coll Abbottabad 2009;21(3).

41. Wood P. An appreciation of mitral stenosis, Clinical features. $\mathrm{Br}$ Med J 1954; 4870:1051-63.

42. Rowe JC, Bland EF, Sprague HB, White PD. The course of mitral stenosis without surgery ten- and twenty-year perspectives. Ann Intern Med 1960;52:741-49.

43. Bonow RO, Carabello BA, Chatterjee K, et al: ACC/AHA 2006 guidelines for the management of patients with valvular heart disease: A report of the American College of Cardiology/American Heart Association Task Force on Practice Guidelines (writing committee to revise the 1998 Guidelines for the Management of Patients with Valvular Heart Disease): Developed in collaboration with the Society of Cardiovascular Anesthesiologists: endorsed by the Society for Cardiovascular Angiography and Interventions and the Society of Thoracic Surgeons. Circulation 114:e84, 2006; Zoghbi WA, Enriquez-Sarano M, Foster E, et al: Recommendations for evaluation of the severity of native valvular regurgitation with twodimensional and Doppler echocardiography. J Am Soc Echocardiogr 2003;16:777.

44. Shahbudin H.Rahimtoola. valvular heart disease:mitral valve stenosis. Hurst's The Heart, Volume 1, 12th edition,2007;1757-69.

45. Catherine M.Otto ,Robert O.Bonow.Valvular heart Disease. In, Braunwald's Heart Disease A Textbook of Cardiovascular Medicine. Libby P, Bonow RO, Mann DL, Zipes DP. 9th edition. Saunders. New York:1468-1520.

46. Patrick O'Gare, Joseph Loscalzo. Valvular heart disease. Harrison's principle of internal medicine, 18th Edition.2012;192950.

47. Rahimtoola SH. Valvular heart disease. In: Stein J, ed. Internal Medicine, 4thed. St. Louis: Mosby-Year Book, 1994:202-34.

48. Mensah GA. The burden of valvular heart disease. In Otto CM.BONOW RO:valvular heart disease: a companion to braunwalds heart disease. philadelphia, saunders/Elseveir, 2009;1-
18.

49. Essop MR,Nkomo VT: Rheumatic and non rheumatic valvular heart disease. Epidemiology, management and prevention in Africa. Circulation 2005; 112:35-84.

50. BENJAMIN SHIPTON,HANEY WAHBA. Valvular Heart Disease: Review and Update.Am Fam Physician. 2001;63(11):2201-09.

51. Robert A. O' Rourke, Louis J. Dell' Italia. Valvular heart disease: Mitral valve regurgitation including the mitral valve prolapse syndrome. Hurst's The Heart, Volume 1, 12th edition,2007;173142.

52. Roberts WC, Perloff JK. Mitral valve disease. A clinicopathologic survey of the conditions causing the mitral valve to function abnormally. Ann Intern Med 1972;77(6):939-975.

53. Shahbudin H.Rahimtoola. valvular heart disease:Aortic valve disease. Hurst's The Heart, Volume 1, 12th edition,2007;16971727.

54. Pravin M. Shah . valvular heart disease: Tricuspid valve, pulmonary valve \& multivalvular disease. Hurst's The Heart, Volume 1, 12th edition,2007;1770-81.

55. Joseph loscalzo. Approach to the patient with possible cardiovascular disease. Harrison's principle of internal medicine, 18th Edition.2012;1818.

56. Robert A, O' Rourke, Janes A.Shaver, Mark E.Silverman. The History, Physical examination examination, and cardiac Auscultation. Hurst's The Heart, Volume 1 , 12th edition, 2007;216-23.

57. Joseph Loscalzo. Palpitations. . Harrison's principle of internal medicine, 18th Edition.volume 12.2012;295.

58. Mark callaway, peter wilde. Acquired heart disease I: the chest radiograph. In,David Sutton(ed) vol I.text book of radiology and imaging, $7 \mathrm{TH}$ edition,Edinburgh Elsevier science publishers, 2003; 293.

59. S.padmavati .Epidemiology of cardiovascular disease in India. Rheumaticheart disease.Circulation 1962;25:703-10.

60. Bayer AS, Ward JI, Ginzton LE, Shapiro SM. Evaluation of new clinical criteria for the diagnosis of infective endocarditis. Am J Med 1994 Mar;96(3):211-19.
Conflict of Interest: Nil

Source of Support: None
Full Thesis and Master Chart available on www.journalmedicalthesis.com

How to Cite this Article:

Lakhani SV \& Joglekar VK. Clinical Study of Valvular Heart Disease. Journal Medical Thesis 2013 July-Sep; 1(1):8-11 